\title{
Meat and Fish as Sources of Extended-Spectrum $\beta$-Lactamase- Producing Escherichia coli, Cambodia
}

\author{
Maya Nadimpalli, Yith Vuthy, \\ Agathe de Lauzanne, Laetitia Fabre, \\ Alexis Criscuolo, Malika Gouali, \\ Bich-Tram Huynh, Thierry Naas, Thong Phe, \\ Laurence Borand, Jan Jacobs, \\ Alexandra Kerléguer, Patrice Piola, \\ Didier Guillemot, Simon Le Hello, ${ }^{1}$ \\ Elisabeth Delarocque-Astagneau, ${ }^{1}$ \\ on behalf of the BIRDY study group ${ }^{2}$
}

We compared extended-spectrum $\beta$-lactamase-producing Escherichia coli isolates from meat and fish, gut-colonized women, and infected patients in Cambodia. Nearly half of isolates from women were phylogenetically related to foodorigin isolates; a subset had identical multilocus sequence types, extended-spectrum $\beta$-lactamase types, and antimicrobial resistance patterns. Eating sun-dried poultry may be an exposure route.

$\mathrm{I}_{\mathrm{B}-\mathrm{m}}^{\mathrm{n}}$ Europe, evidence for the spread of extended-spectrum $\beta$-lactamase (ESBL)-producing Escherichia coli from animals to humans via food is unclear (1). Few studies have been conducted in low- and middle-income countries, where colonization rates can exceed 60\% (2). High ESBL colonization rates in low- and middle-income countries such as Cambodia are usually attributed to unrestricted consumer access to and hospital overuse of third-generation cephalosporins $(3,4)$. How-

Author affiliations: Institut Pasteur, Paris, France (M. Nadimpalli,

L. Fabre, A. Criscuolo, B.-T. Huynh, D. Guillemot, S. Le Hello,

E. Delarocque-Astagneau); Institut National de la Santé et de la

Recherche Médicale, Université de Versailles Saint-Quentin-en-

Yvelines and Université Paris-Saclay, Paris (M. Nadimpalli,

B.-T. Huynh, D. Guillemot, E. Delarocque-Astagneau); Institut

Pasteur du Cambodge, Phnom Penh, Cambodia (Y. Vuthy,

A. de Lauzanne, M. Gouali, L. Borand, A. Kerléguer, P. Piola);

Assistance Publique/Hôpitaux de Paris, Bicêtre Hospital and

Université Paris-Sud, Le Kremlin-Bicêtre, France (T. Naas);

Sihanouk Hospital Center of Hope, Phnom Penh (T. Phe);

Institute of Tropical Medicine, Antwerp, Belgium (J. Jacobs);

K.U. Leuven, Leuven, Belgium (J. Jacobs); Assistance Publique/

Hôpitaux de Paris, Raymond-Poincaré Hospital, Garches, France

(D. Guillemot, E. Delarocque-Astagneau)

DOI: https://doi.org/10.3201/eid2501.180534 ever, antimicrobial drugs in classes critical for human health (e.g., $\beta$-lactams, macrolides, aminoglycosides, polymyxins) are increasingly being used in food animals (5). In Cambodia, weak public health protections and consumption of undercooked animal products could exacerbate the spread of ESBLproducing $E$. coli or ESBL genes from animals to humans.

We had 2 goals with this study. First, we assessed the prevalence of ESBL-producing or carbapenemase-producing E. coli from fish, pork, and chicken from markets in Phnom Penh, Cambodia. Second, we examined the contribution of food-origin isolates to locally disseminated ESBL E. coli by comparing isolates from food with isolates from healthy, colonized persons and infected patients.

\section{The Study}

During September-November 2016, we purchased 60 fish, 60 pork, and 30 chicken samples from 150 vendors at 2 markets in Steung Meanchey district, Phnom Penh (Appendix Table 2, https://wwwnc.cdc.gov/EID/article/25/1/180534-App1.pdf) and tested them at the Institut Pasteur du Cambodge for third-generation cephalosporin- and carbapenem-resistant E. coli (Appendix sections 1.1-1.3). We detected ESBL-producing E. coli (all CTX-M-type) among $93(62 \%)$ of 150 food samples, including $32(53 \%)$ of 60 fish, 45 (75\%) of 60 pork, and 16 (53\%) of 30 chicken samples. We identified carbapenem-resistant E. coli (OXAtype) from 1 pork and 1 fish sample.

We also selected ESBL-producing E. coli from 88 recently pregnant healthy women living in Steung Meanchey and participating in the Bacterial Infections and antibiotic Resistant Diseases among Young children in low-income countries (BIRDY) program, a surveillance program of bacterial infections among young children in low- and middleincome countries (6). During September 2015-December 2016, ESBL-producing E. coli isolates were cultured from rectal swabs or fecal samples collected at or just after delivery (Appendix Table 3).

We further included ESBL-producing E. coli from 15 Phnom Penh-based patients who sought care at the Sihanouk Hospital Center of Hope during November 2015-

${ }^{1}$ These senior authors contributed equally to this article.

${ }^{2}$ Additional members of the BIRDY study group are listed at the end of this article. 


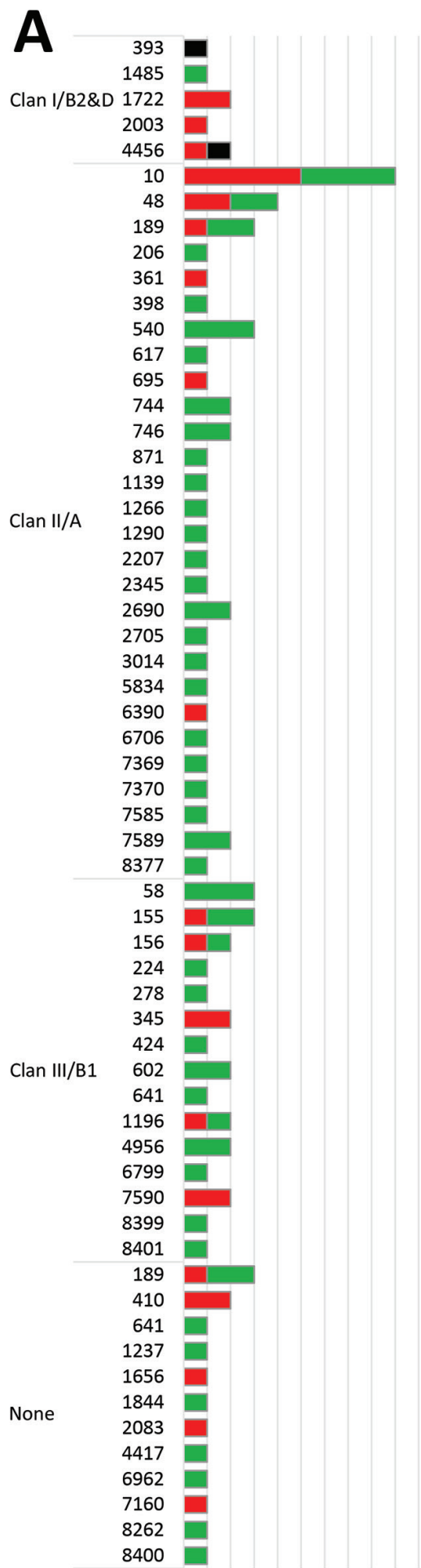

$\begin{array}{lllllllllll}0 & 1 & 2 & 3 & 4 & 5 & 6 & 7 & 8 & 9 & 10\end{array}$

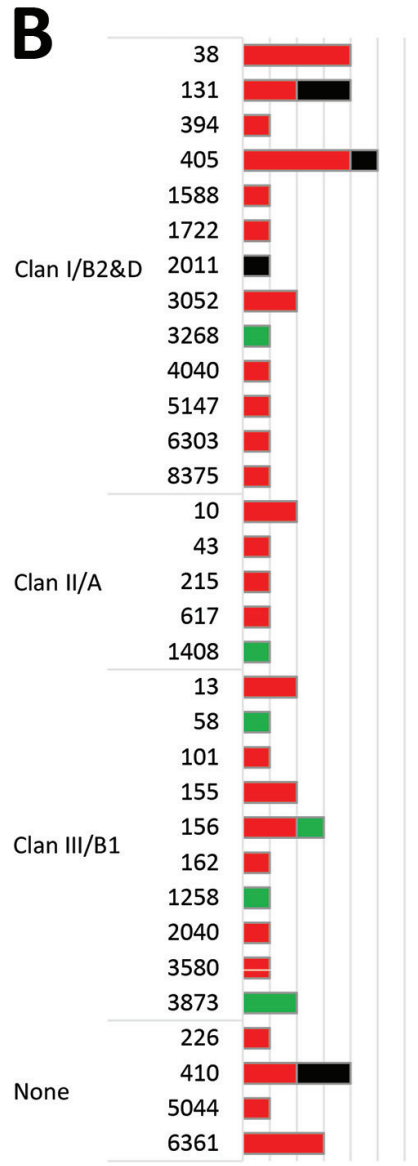

0123456
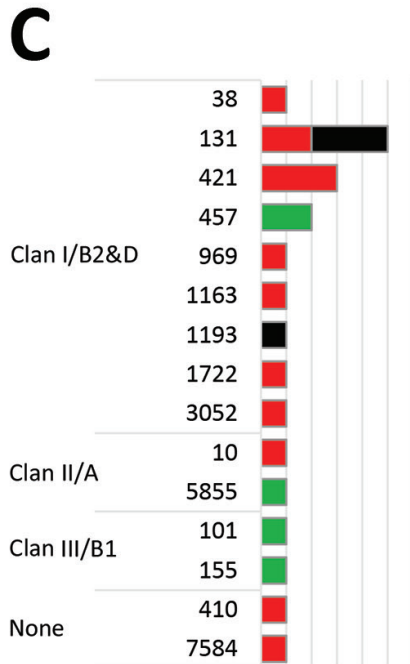

0123456

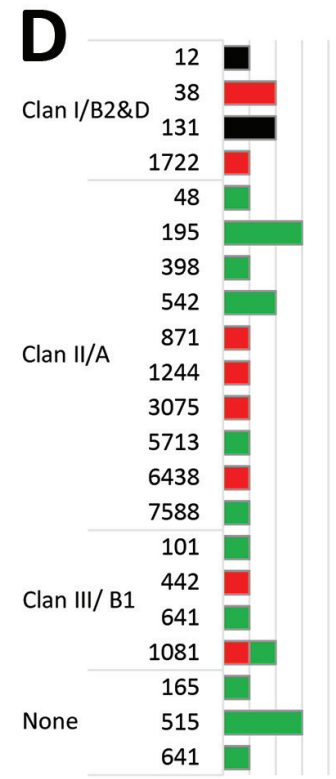

01234
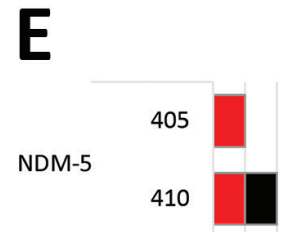

NDM-1 101

10

OXA-181 410

$\begin{array}{llll}0 & 1 & 2 & 3\end{array}$

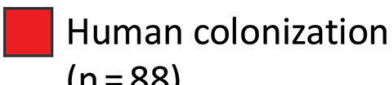
$(n=88)$

Human infection $(n=15)$

Meat and fish $(n=93)$

Figure 1. Distribution of 105 multilocus sequence types (MLSTs) among predominant extended-spectrum $\beta$-lactamase (ESBL) and carbapenemase gene types encoded by 196 ESBL-producing Escherichia coli from humans and food, Cambodia, 2015-2016.

A) CTX-M-55; B) CTX-M15; C) CTX-M-27; D) CTX-M-14; E) carbapenemases. Vertical axes depict MLSTs. Horizontal axes depict the frequency of each observed MLST. CTX-M-3, CTX-M-24, and CTX-M-65 are not shown because these ESBL gene types were rare (<2\%). One human colonization isolate (ST394, clan I/B2\&D) encoded CTX-M-3, 1 food-origin isolate (ST10, clan II/A) encoded CTX-M-24, and 2 food-origin isolates (ST2207, clan II/A and ST7586, clan III/B1) encoded CTX-M-65. 
December 2016. ESBL-producing E. coli were cultured from blood (12 patients), urine (2 patients), and peritoneal fluid (1 patient) (Appendix Table 4).

We performed whole-genome sequencing for 1 ESBL -producing $E$. coli isolate from each food sample and all human-origin ESBL-producing E. coli isolates (Appendix sections 1.4-1.6) and compiled genetic and phenotypic characteristics of these 196 isolates (Appendix Tables 6, 7). We also determined the distribution of multilocus sequence types (MLSTs) encoding predominant ESBL- or carbapenemase-gene types (Figure 1).

Phylogenetic analysis of ESBL-producing E. coli genomes revealed 3 distinct clans (Figure 2, panel A). Clan I/ $\mathrm{B} 2 \& \mathrm{D}(\mathrm{n}=53)$ comprised mostly human-origin isolates, including isolates from colonized persons and most infected patients. Clans II/A $(n=69)$ and III/B1 $(n=47)$ included isolates from colonized persons and from food but not from infected patients. Each clan comprised an exclusive subset of sequence types (STs); clan I/B2\&D included ST131 and clonal complex (CC) 38, clan II/A included CC10, and clan III/B1 included CC58 and CC156. Approximately half (21/39) of isolates in clans II/A and III/B1 from colonized patients belonged to STs detected in both humans and meat (Appendix Table 8).
We determined the distributions of ESBL-encoding genes and resistance patterns among isolates from colonized persons by clan (Figure 2, panels B and C). The bla $a_{\text {CTX-M- } 55}$ gene was more common among colonization isolates belonging to clan II/A than to clan I/B2\&D ( $<<0.05)$. Amphenicol resistance was more common among colonization isolates belonging to clan II/A than clan I/B2\&D $(\mathrm{p}<0.05)$ and was most often encoded by floR (Appendix Table 7).

Women colonized with amphenicol-resistant (vs. amphenicol-susceptible) ESBL-producing E. coli were more likely to report having ever eaten dried poultry (adjusted odds ratio 9.0, 95\% CI 1.8-45.2) (Table). Women colonized with CTX-M-55-producing E. coli (vs. other ESBL types) were more likely to have handled live poultry (adjusted odds ratio $4.6,95 \%$ CI 1.1-19.3), but this exposure was uncommon $(11 / 88)$.

Our genomic and epidemiologic findings suggest that ESBL-producing $E$. coli that contaminates meat and fish in Phnom Penh may be disseminating to the community. ESBL-producing $E$. coli were highly prevalent among the meat and fish we sampled. More than $80 \%$ of food-origin isolates were amphenicol resistant, and two thirds produced CTX-M-55. When food-origin isolates were compared

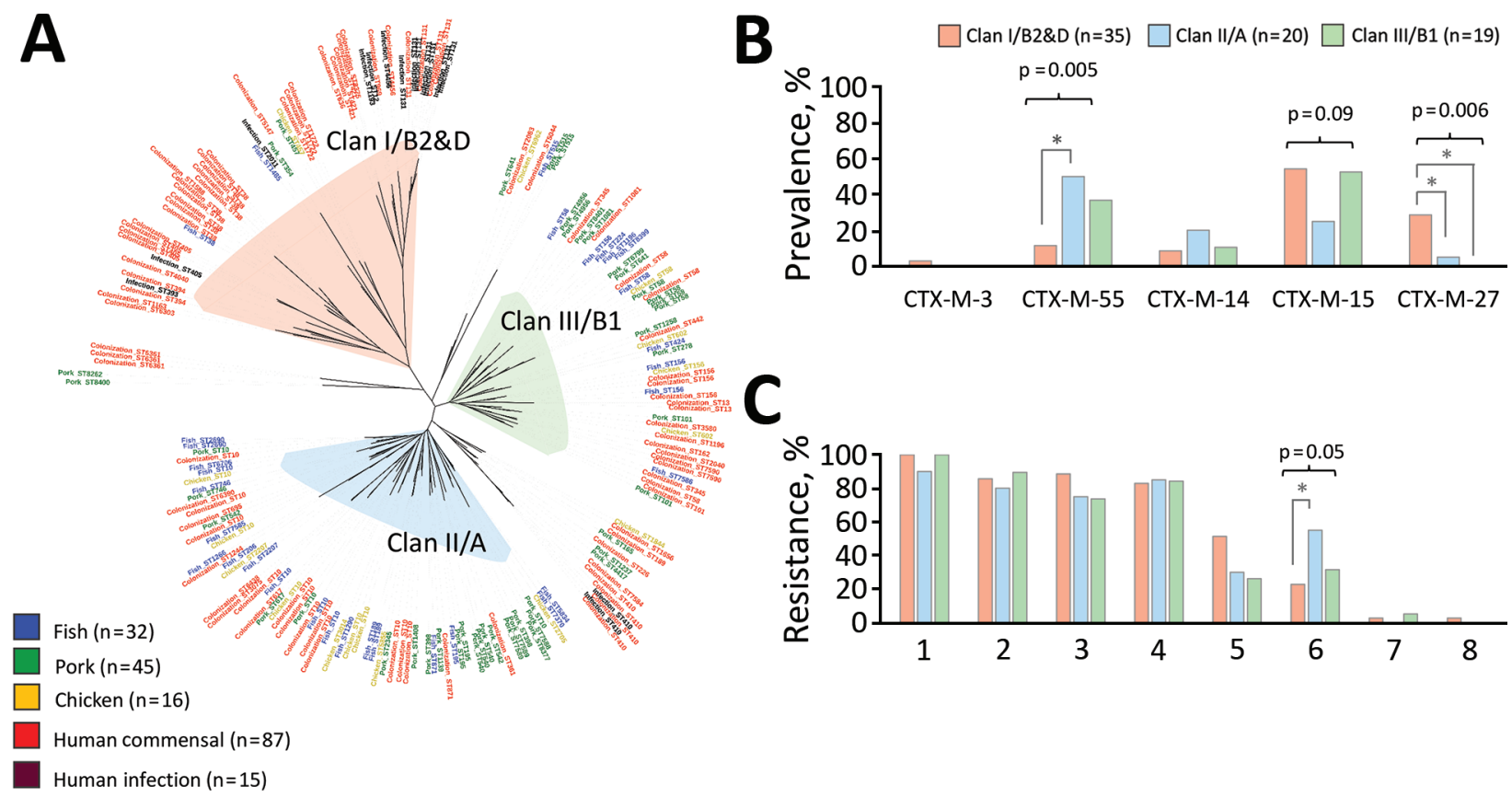

Figure 2. Genomic comparisons of extended-spectrum $\beta$-lactamase (ESBL)-producing Escherichia coli from humans, fish, pork, and chicken from Cambodia and differences in human colonization isolates by phylogenetic clan. All isolates were phenotypically resistant to third-generation cephalosporins (data not shown). A) Whole-genome sequence-based phylogenetic tree of $195 \mathrm{ESBL}-\mathrm{producing} E$. coli genomes comprising 87 human colonization isolates, 15 human clinical isolates, and 93 isolates from fish, pork, and chicken meat and resulting phylogenetic clans I/B2\&D ( $n=53), I I / A(n=69)$, and III/B1 $(n=47)$. B) ESBL-encoding genes of human colonization $E$. coli isolates, by phylogenetic clan. C) Phenotypic resistance of human colonization ESBL-producing $E$. coli isolates to antimicrobial drugs of 8 classes, by phylogenetic clan. Clinical isolates are not included in panels B or C. Of 87 human colonization genomes, 13 did not group into a phylogenetic clan and thus are excluded from panels B and C. Prevalence of outcome differed significantly $(p<0.05$, indicated by *) between 2 indicated clans by post hoc Tukey test. Only statistically significant differences are depicted. 1, quinolone; 2 , co-trimoxazole; 3 , tetracycline; 4, aminoglycoside; 5, macrolide; 6, amphenicol; 7, carbapenem; 8, colistin. 
with human-origin isolates, $\approx 40 \%$ of ESBL-producing E.coli from healthy persons grouped into the same phylogenetic clans that comprised most food-origin isolates. Approximately half of these colonization isolates had MLSTs detected among food, and a substantial portion were more likely to produce CTX-M-55 and be amphenicol resistant than colonization isolates that grouped separately. The fact that chloramphenicol has not been used in human medicine for almost 20 years in Cambodia, yet chloramphenicol analogs (e.g., florfenicol, thiamphenicol) are administered to food animals $(5,7)$, suggests a food origin for these colonizing isolates.

Healthy women colonized with amphenicol-resistant ESBL-producing $E$. coli were more likely to eat poultry meat prepared by sun drying, a process that may not eliminate bacteria (8). Although we did not test dried meat samples for ESBL-producing $E$. coli contamination, our finding is consistent with those of other studies $(8,9)$. Women reported having prepared dried poultry at home. Especially in lowresource households, sun-dried meat may become crosscontaminated by raw meat, dust, animals, and flies (8).

Our findings are concerning because of growing interest in using chloramphenicol as a drug of last resort for panresistant strains of bacteria (10). In the early 2000 s, the Cambodia government stopped purchasing chloramphenicol because of concerns about side effects. Since restriction of this drug, infections in the hospital setting have reverted to a chloramphenicol-susceptible phenotype (11). Nevertheless, our findings suggest that amphenicol resistance genes are circulating in the

\begin{tabular}{|c|c|c|c|c|c|c|c|c|}
\hline \multirow[b]{2}{*}{ Variable } & \multicolumn{4}{|c|}{$\mathrm{CHL}$ resistance } & \multicolumn{4}{|c|}{ ESBL type } \\
\hline & $\begin{array}{c}\text { Resistant, } \\
\text { no. }(\%) \\
\text { n = } 29\end{array}$ & $\begin{array}{c}\text { Susceptible, } \\
\text { no. }(\%) \\
\text { n = } 59\end{array}$ & $\begin{array}{c}\text { OR } \\
(95 \% \mathrm{Cl})\end{array}$ & $\begin{array}{l}\text { aOR }(95 \% \\
\mathrm{Cl})\end{array}$ & $\begin{array}{c}\text { CTX-M-55, } \\
\text { no. }(\%), \\
\text { n = } 26 \\
\end{array}$ & $\begin{array}{c}\text { Other, } \\
\text { no. (\%), } \\
\text { n = 62 }\end{array}$ & $\begin{array}{c}\text { OR } \\
(95 \% \mathrm{Cl}) \\
\end{array}$ & $\begin{array}{c}\text { aOR } \\
(95 \% \mathrm{Cl}) \\
\end{array}$ \\
\hline \multicolumn{9}{|l|}{ Persons living in home } \\
\hline$>8$ & $5(17)$ & $10(17)$ & $\begin{array}{c}1.1 \\
(0.3-3.7)\end{array}$ & & $3(12)$ & $12(19)$ & $\begin{array}{l}0.6 \\
(0.1-2.5)\end{array}$ & \\
\hline $6-8$ & $9(31)$ & $19(32)$ & $\begin{array}{c}1.1 \\
(0.3-3.7)\end{array}$ & & $10(38)$ & $18(29)$ & $\begin{array}{c}1.4 \\
(0.5-3.7)\end{array}$ & \\
\hline$\leq 5$ & $15(52)$ & $30(51)$ & Referent & & $13(50)$ & $32(52)$ & Referent & \\
\hline \multicolumn{9}{|l|}{ Place of delivery } \\
\hline Private clinic & $5(17)$ & $17(29)$ & $\begin{array}{c}0.4 \\
(0.1-1.4)\end{array}$ & & $4(15)$ & $18(29)$ & $\begin{array}{c}0.4 \\
(0.1-1.4)\end{array}$ & \\
\hline Hospital & $11(38)$ & $20(34)$ & $\begin{array}{c}0.8 \\
(0.3-2.2)\end{array}$ & & $9(35)$ & $22(35)$ & $\begin{array}{c}0.7 \\
(0.2-1.9)\end{array}$ & \\
\hline Health center & $13(45)$ & $22(37)$ & Referent & & $13(50)$ & $22(35)$ & Referent & \\
\hline $\begin{array}{l}\text { Received antimicrobial } \\
\text { drugs at delivery } \dagger\end{array}$ & $2(7)$ & $11(19)$ & $\begin{array}{c}0.3 \\
(0.1-1.3)\end{array}$ & $\begin{array}{c}0.2 \\
(0.0-1.1)\end{array}$ & $1(4)$ & $12(19)$ & $\begin{array}{c}0.2 \\
(0-1.3)\end{array}$ & $\begin{array}{c}0.2 \\
(0.0-1.4)\end{array}$ \\
\hline Untreated drinking water & $5(17)$ & $7(12)$ & $\begin{array}{c}1.5 \\
(0.4-5.3)\end{array}$ & & $4(15)$ & $8(13)$ & $\begin{array}{c}1.2 \\
(0.3-4.5)\end{array}$ & \\
\hline Toilet shared $\ddagger$ & $11(38)$ & $16(27)$ & $\begin{array}{c}1.6 \\
(0.6-4.2)\end{array}$ & & $5(19)$ & $22(35)$ & $\begin{array}{c}0.4 \\
(0.1-1.3)\end{array}$ & \\
\hline Nonflush toilet & $26(90)$ & $47(80)$ & $\begin{array}{c}2.2 \\
(0.6-8.5)\end{array}$ & & $24(92)$ & $49(79)$ & $\begin{array}{c}3.2 \\
(0.7-15.3)\end{array}$ & \\
\hline Pet contact & $6(21)$ & $13(22)$ & $\begin{array}{c}0.9 \\
(0.3-2.7)\end{array}$ & & $6(23)$ & $13(21)$ & $\begin{array}{c}1.1 \\
(0.4-3.4)\end{array}$ & \\
\hline Live poultry contact & $4(14)$ & $7(12)$ & $\begin{array}{c}1.2 \\
(0.3-4.4)\end{array}$ & & $6(23)$ & $5(8)$ & $\begin{array}{c}3.4 \\
(0.9-12.4)\end{array}$ & $\begin{array}{c}4.6 \\
(1.1-19.3)\end{array}$ \\
\hline \multicolumn{9}{|l|}{ Consumption habits } \\
\hline Dried pork $\geq 1 \times /$ wk & $15(52)$ & $32(54)$ & $\begin{array}{c}0.9 \\
(0.4-2.2)\end{array}$ & & $11(42)$ & $36(58)$ & $\begin{array}{c}0.5 \\
(0.2-1.3)\end{array}$ & \\
\hline Dried beef & $17(59)$ & $38(64)$ & $\begin{array}{c}0.8 \\
(0.3-2.1)\end{array}$ & & $20(77)$ & $35(56)$ & $\begin{array}{c}2.6 \\
(0.9-7.3)\end{array}$ & \\
\hline Dried poultry & $27(93)$ & $39(66)$ & $\begin{array}{c}7.9 \\
(1.7-36.4)\end{array}$ & $\begin{array}{c}9.0 \\
(1.8-45.2)\end{array}$ & $22(85)$ & $44(71)$ & $\begin{array}{c}2.3 \\
(0.7-7.5)\end{array}$ & \\
\hline Pork $\geq 3 \times /$ wk & $22(76)$ & $53(90)$ & $\begin{array}{c}0.4 \\
(0.1-1.2)\end{array}$ & $\begin{array}{c}0.2 \\
(0.1-1.1)\end{array}$ & $23(88)$ & $52(84)$ & $\begin{array}{c}1.5 \\
(0.4-5.9)\end{array}$ & \\
\hline Insects & $21(72)$ & $33(56)$ & $\begin{array}{c}2.2 \\
(0.8-5.7)\end{array}$ & & $16(62)$ & $38(61)$ & $\begin{array}{c}1 \\
(0.4-2.6)\end{array}$ & \\
\hline Raw vegetables $\geq 1 \times /$ wk & $5(17)$ & $8(14)$ & $\begin{array}{c}1.3 \\
(0.4-4.5)\end{array}$ & & $3(12)$ & $10(16)$ & $\begin{array}{c}0.7 \\
(0.2-2.7)\end{array}$ & \\
\hline
\end{tabular}

*Blank cells indicate variable not included in multivariate models. aOR, adjusted (for age) OR; CHL, chloramphenicol; ESBL, extended-spectrum $\beta$ lactamase; OR, odds ratio.

†Not reported for 4 women (missing data). All 4 were colonized with CHL-susceptible ESBL-producing Escherichia coli. One woman was colonized with CTX-M-55-type E. coli, whereas the other 3 were colonized with other CTX-M-encoded isolates. ¥With persons in other households. 
community, potentially because amphenicol use in food animals has selected for resistant bacteria that can spread to humans (12). This possibility is concerning because physicians in Cambodia are often unable to assess the resistance of infectious agents before prescribing antimicrobial drugs (4).

Our study had several limitations. First, for logistical reasons, we sampled meat and fish during only 1 season. Contamination rates may have differed had we sampled across seasons (13). Second, although we included colonization samples from healthy women, all women had recently given birth in healthcare settings. However, more than half were colonized with ESBL-producing $E$. coli phylotypes A and B1, supporting community-associated, rather than healthcare-associated, acquisition. Third, we were unable to include clinical isolates from the same population that contributed colonization isolates. Thus, differences in colonization and clinical isolates could have resulted from population differences. Fourth, we did not sample food animals, which could have helped confirm that CTX-M-55-type and amphenicol-resistant ESBL-producing E. coli circulate among them. Last, we did not investigate additional potential pathways for ESBLproducing $E$. coli transmission to colonized women, such as contact with persons employed at farms or slaughterhouses or proximity to such operations.

\section{Conclusions}

This study, which integrated epidemiologic and genomic methods to characterize community, clinical, and environmental data, supports concerns that the dissemination of antimicrobial drug-resistant bacteria from food animals to humans may be more likely in low- and middle-income countries $(14,15)$. This finding is concerning because meat consumption is projected to drastically increase in these countries, and animal production that relies on routine antimicrobial drug use is being promoted to meet this demand (14). Particularly for low- and middle-income countries such as Cambodia, implementation of multisectoral strategies to combat antimicrobial resistance from a One Health perspective must be supported, and food safety should be prioritized.

Collaborators of the BIRDY program: Bodonirina Tanjona Raheliarivao, Frédérique Randrianirina, Perlinot Herindrainy, Zafitsara Zo Andrianirina, Feno Manitra Jacob Rakotoarimanana, Benoit Garin, Jean-Marc Collard, Thida Chon, Sok Touch, Arnaud Tarantola, Sophie Goyet, Siyin Lach, Veronique Ngo, Muriel Vray, Marguerite Diatta, Joseph Faye, Abibatou Ndiaye, Vincent Richard, Abdoulaye Seck, Raymond Bercion, Amy Gassama Sow, Jean Baptiste Diouf, Pape Samba Dieye, Balla Sy, Bouya Ndao, Maud Seguy, Laurence Watier, Abdou Armya Youssouf, and Michael Padget.

\section{Acknowledgments}

We thank Kruy Sun Lay for assistance with field study design and implementation; Moul Chanta for collection of meat samples and questionnaire administration; Yem Chailly for questionnaire administration to BIRDY-enrolled women; Sem Nita and Magali Ravel for assistance with laboratory analyses; and all physicians, laboratory staff, field interviewers, and community workers involved in the project. We also thank the Plateforme de Microbiologie Mutualisée of the Pasteur International Bioresources Network from the Institut Pasteur of Paris for genomic sequencing. We are grateful to all women participating in the BIRDY program.

This work was supported by the Dennis and Mireille Gillings Foundation, the US Pasteur Foundation, MSD Avenir, the Monaco Department of International Cooperation, and the Institut Pasteur. The funders had no role in study design, data collection and analysis, decision to publish, or preparation of the manuscript.

\section{About the Author}

Dr. Nadimpalli is a postdoctoral research scientist at the Institut Pasteur. She is interested in using genomic and epidemiologic approaches to understand how exposures to animals and the environment can affect human colonization and infection with antimicrobial-resistant bacteria.

\section{References}

1. Lazarus B, Paterson DL, Mollinger JL, Rogers BA. Do human extraintestinal Escherichia coli infections resistant to expandedspectrum cephalosporins originate from food-producing animals? A systematic review [cited 2017 Nov 3]. https://academic.oup.com/ cid/article-lookup/doi/10.1093/cid/ciu785

2. Woerther P-L, Burdet C, Chachaty E, Andremont A. Trends in human fecal carriage of extended-spectrum $\beta$-lactamases in the community: toward the globalization of CTX-M. Clin Microbiol Rev. 2013;26:744-58. http://dx.doi.org/10.1128/ CMR.00023-13

3. Laxminarayan R, Duse A, Wattal CM, Zaidi AKL, Wertheim HF, Sumpradit N, et al. Antibiotic resistance - the need for global solutions. Lancet Infect Dis. 2013;13:1057-98. http://dx.doi.org/ 10.1016/S1473-3099(13)70318-9

4. Om C, Daily F, Vlieghe E, McLaughlin JC, McLaws M-L. "If it's a broad spectrum, it can shoot better": inappropriate antibiotic prescribing in Cambodia. Antimicrob Resist Infect Control. 2016;5:58. http:dx.doi.org/10.1186/s13756-016-0159-7

5. Ström G, Boqvist S, Albihn A, Fernström L-L, Andersson Djurfeldt A, Sokerya $\mathrm{S}$, et al. Antimicrobials in small-scale urban pig farming in a lower middle-income country-arbitrary use and high resistance levels [cited 2018 May 29]. https://aricjournal.biomedcentral.com/ articles/10.1186/s13756-018-0328-y

6. Huynh B-T, Kermorvant-Duchemin E, Herindrainy P, Padget M, Rakotoarimanana FMJ, Feno H, et al. Bacterial infections in neonates, Madagascar, 2012-2014. Emerg Infect Dis. 2018;24:710-17. https://dx.doi.org/10.3201/eid2404.161977

7. Nhung NT, Cuong NV, Thwaites G, Carrique-Mas J. Antimicrobial usage and antimicrobial resistance in animal production in Southeast Asia: a review. Antibiotics (Basel). 2016;5:E37. http://dx.doi.org/10.3390/antibiotics5040037 
8. Food Safety and Inspection Service. Jerky and food safety [cited 2018 Feb 6]. https://www.fsis.usda.gov/wps/portal/fsis/topics/ food-safety-education/get-answers/food-safety-fact-sheets/ meat-preparation/jerky-and-food-safety/CT_Index

9. Niumsup PR, Tansawai U, Na-udom A, Jantapalaboon D, Assawatheptawee K, Kiddee A, et al. Prevalence and risk factors for intestinal carriage of CTX-M-type ESBLs in Enterobacteriaceae from a Thai community. Eur J Clin Microbiol Infect Dis. 2018;37:69-75. https://dx.doi.org/10.1007/s10096-017-3102-9

10. Falagas ME, Grammatikos AP, Michalopoulos A. Potential of old-generation antibiotics to address current need for new antibiotics [cited 2017 Nov 2]. http://www.tandfonline.com/doi/ full/10.1586/14787210.6.5.593

11. Fox-Lewis A, Takata J, Miliya T, Lubell Y, Soeng S, Sar P, et al. Antimicrobial resistance in invasive bacterial infections in hospitalized children, Cambodia, 2007-2016. Emerg Infect Dis. 2018; 24:841-51.

12. Trongjit S, Angkittitrakul S, Chuanchuen R. Occurrence and molecular characteristics of antimicrobial resistance of Escherichia coli from broilers, pigs and meat products in Thailand and Cambodia provinces. Microbiol Immunol. 2016;60:575-85. http://dx.doi.org/10.1111/1348-0421.12407
13. Cohen N, Ennaji H, Bouchrif B, Hassar M, Karib H. Comparative study of microbiological quality of raw poultry meat at various seasons and for different slaughtering processes in Casablanca (Morocco). J Appl Poult Res. 2007;16:502-8. http://dx.doi.org/ 10.3382/japr.2006-00061

14. Lam Y, Fry JP, Hu E, Kim BF, Nachman KE. Industrial food animal production in low-and middle-income countries: a landscape assessment [cited 2017 Nov 3]. https://www.jhsph.edu/ research/centers-and-institutes/johns-hopkins-center-for-alivable-future/_pdf/projects/IFAP/IFAPLowmid_income countriesWeb1.pdf

15. Nadimpalli M, Delarocque-Astagneau E, Love DC, Price LB, Huynh BTB-T, Collard JMJ-M, et al.; Bacterial Infections and antibiotic-Resistant Diseases among Young children in lowincome countries (BIRDY) study group. Combating global antibiotic resistance: emerging One Health concerns in lowerand middle-income countries. Clin Infect Dis. 2018;66:963-9. http://dx.doi.org/10.1093/cid/cix879

Address for correspondence: Maya Nadimpalli, Institut Pasteur, 25 Rue du Docteur Roux, 75724 Paris CEDEX 15, France; email: maya.nadimpalli@gmail.com

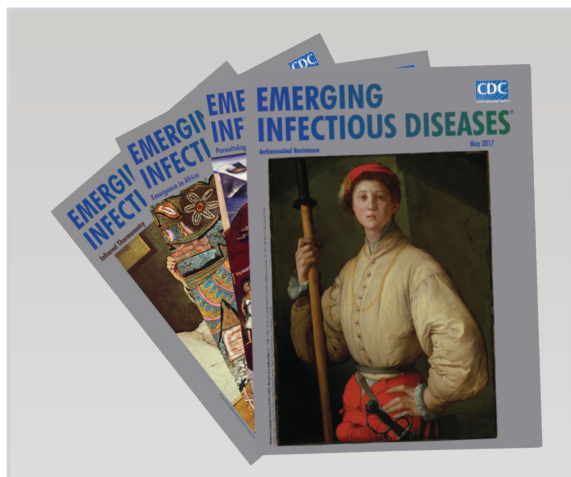

- Exposure Characteristics of Hantavirus Pulmonary Syndrome Patients, United States, 1993-2015

- Increased Neurotropic Threat from Burkholderia pseudomallei Strains with a $B$. mallei-like Variation in the $\operatorname{bimA}$ Motility Gene, Australia

- Population Genomics of Legionella longbeachae and Hidden Complexities of Infection Source Attribution

- Prevention of Chronic Hepatitis B after 3 Decades of Escalating Vaccination Policy, China

- Lack of Durable Cross-Neutralizing Antibodies against Zika Virus from Dengue Virus Infection

- Use of Blood Donor Screening Data to Estimate Zika Virus Incidence, Puerto Rico, April-August 2016

- Invasive Nontuberculous Mycobacterial Infections among Cardiothoracic Surgical Patients Exposed to HeaterCooler Devices

- Anthrax Cases Associated with Animal-Hair Shaving Brushes

- Increasing Macrolide and Fluoroquinolone Resistance in Mycoplasma genitalium
EMERGING INFECTIOUS DISEASES May 2017

\section{Antimicrobial Resistance}

- Population Responses during the Pandemic Phase of the Influenza A(H1N1)pdm09 Epidemic, Hong Kong, China

- Survey of Treponemal Infections in Free-Ranging and Captive Macaques, 1999-2012

- Phenotypic and Genotypic Shifts in Hepatitis B Virus in Treatment-Naive Patients, Taiwan, 2008-2012

- No Such Thing as Chronic Q Fever

- Reassortant Clade 2.3.4.4 Avian Influenza A(H5N6) Virus in a Wild Mandarin Duck, South Korea, 2016

- Amoxicillin and Ceftriaxone as Treatment Alternatives to Penicillin for Maternal Syphilis

- Azithromycin Resistance and Decreased Ceftiraxone Susceptibility in Neisseria gonorrhoeae, Hawaii, USA

- Regional Transmission of Salmonella Paratyphi A, China, 1998-2012

- Exposure Risk for Infection and Lack of Human-to-Human Transmission of Mycobacterium ulcerans Disease, Australia

\section{To revisit the September 2017 issue, go to: https://wwwnc.cdc.gov/eid/articles/issue/23/5/table-of-contents}

